\title{
Electronic Interactions
}

Between Polycyclic Arenes in Cyclophanes

\author{
Matthias W. Haenel ${ }^{1}$ and Dieter Schweitzer ${ }^{2}$ \\ 'Max-Planck-Institut für Kohlenforschung, Kaiser-Wilhelm-Platz I, D-4330 \\ Mülheim a. d. Ruhr, Federal Republic of Germany \\ 'Max-Planck-Institut für medizinische Forschung, Jahnstrasse 29, D-6900 \\ Heidelberg, Federal Republic of Germany
}

The $\pi-\pi$ interaction between polycyclic arenes and the effects of orientation were studied in [2.2]-, [3.3]-, and [3.2]naphthalenophanes, [2]naphthaleno[2]paracyclophanes, and syn- and anti$[2.2](2,7)$ fluorenophane by electron absorption and emission spectroscopy as well as by optically detected magnetic resonance (ODMR) of the excited triplet state. The $\pi-\pi$ interaction in the excited singlet and triplet state was found to be highest if a maximal number of sixmembered rings of the interacting arenes in a parallel orientation are completely eclipsed. Similarly, the $\mathrm{n}-\pi$ interaction between the nonbonding nitrogen electron pair and the aromatic $\pi$ electrons was investigated in isomeric etheno-bridged naphthalenopyridinophanes and an anthracenopyridinophane; in these pyridinophanes, the pyridine rings are fixed perpendicularly above different sites of the naphthalene and anthracene units, respectively.

HE CHARACTERISTIC FEATURE OF BENZENE AND POLYCYCLIC ARENES is the $\pi$-electron system. The overlapping $2 p_{z}$ orbitals on each $s p^{2}$-hybridized carbon center generate an electron cloud over and under a planar hydrocarbon skeleton. This electronic structure favors intermolecular interactions between arenes in a face-to-face geometry (Figure 1). In an electronically 


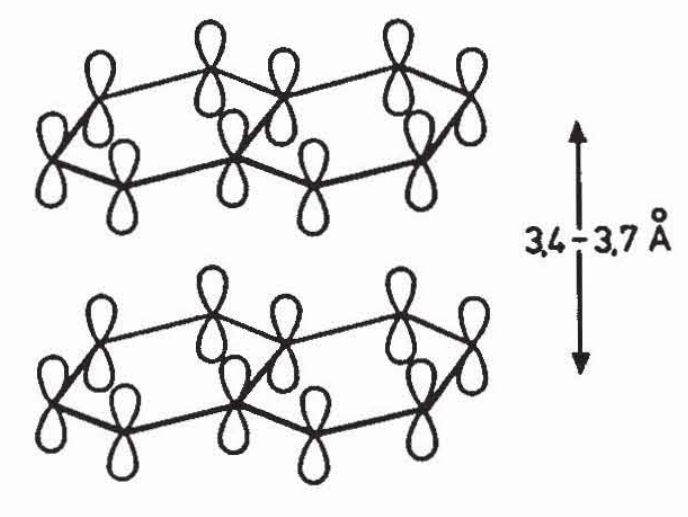

$\pi-\pi-$ Interaction between Arenes

- excimer and exciplex

- donor-acceptor complex or

charge-transfer complex

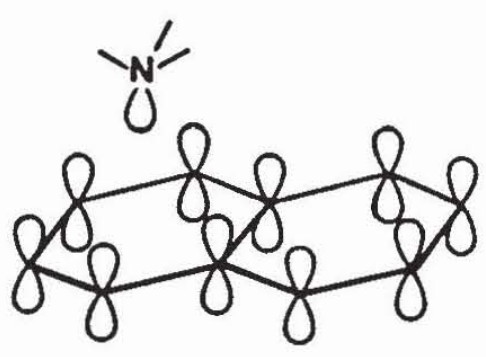

$n-\pi$-Interaction between Amine and Arene

- amine - arene - exciplex

- photoreduction of arenes by amines

Figure 1. Electronic interactions of arenes.

excited state, the binding $\pi-\pi$ interaction leads to the formation of excited dimers or complexes, which are called excimers or exciplexes, respectively $(1-4)$. The electronic ground state usually is attractive only if some charge transfer is induced between electron-donor and electron-acceptor systems (5). A similar $n-\pi$ interaction between a nonbonding nitrogen electron pair and aromatic $\pi$ electrons is involved in the formation of amine-arene exciplexes $(6-8)$ and in the photoreduction of arenes by amines $(9,10)$.

The classic example for the $\pi-\pi$ electron interaction between polycyclic arenes is the pyrene excimer (11). Upon UV excitation of a $10^{-5} \mathrm{M}$ pyrene solution, the structured fluorescence of monomeric pyrene molecules is mainly observed. The increase of the concentration to $10^{-3} \mathrm{M}$ diminishes the monomeric fluorescence, and a new broad and completely structureless excimer band appears, which is red-shifted by $5000-6000 \mathrm{~cm}^{-1}$. This phenomenon can be explained through potential curves of the electronic ground state and the excited singlet state $(1,12)$. The spectroscopic shift between the fluorescence of the excimer and the monomer depends on the depth of the potential well in the excited state; that is, the red shift is proportional to the binding energy of the excimer.

Figure 2 raises the question of how the electronic interaction depends on the orientation. For instance, three different orientations are shown for the naphthalene excimer (Figure 2a). In the amine-anthracene exciplex (Figure 2b), the nitrogen can be located over one of the outer six-membered rings or over the inner six-membered ring of anthracene. At the bottom of Figure $2 b$, an orientation is shown in which the nitrogen is located directly 
a
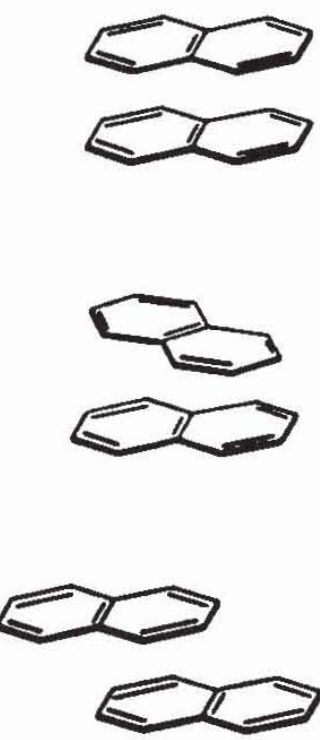

b
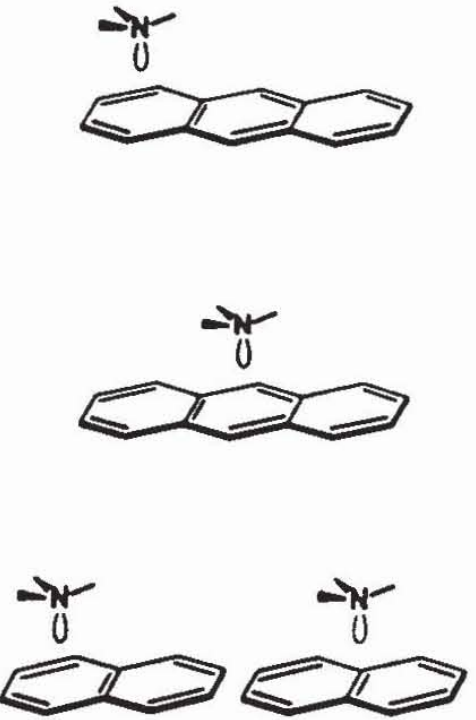

c

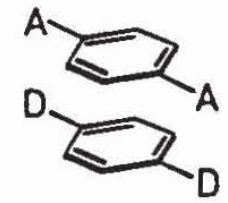

"pseudogeminal"

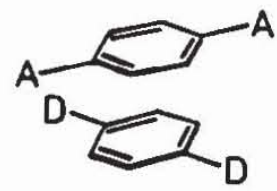

"pseudoortho"

$A=$ electron withdrowing substituent

$D=$ electron donating substituent

Figure 2. Effect of orientation on the electronic interactions of arene excimers

(a), amine-arene exciplexes (b), and charge-transfer complexes (c).

over the central naphthalene $\pi$ bond. Orientation is also important in chargetransfer complexes (Figure 2c). For the complex, which consists of donor and acceptor substituted benzene derivatives, the "pseudogeminal" and "pseudoortho" orientations can be distinguished (13). To investigate these orientational dependencies, we and other groups have synthesized cyclophanes $(14,15)$ in which two aromatic units are immovably arranged by rigid carbon skeletons in different face-to-face orientations. In this chapter, the $\pi-\pi$ electron interaction between polycyclic arenes and the effects of orientation are discussed for [2.2]-, [3.3]-, and [3.2]naphthalenophanes (1-12), isomeric [2]naphthaleno[2]paracyclophanes (13-15), and syn- and anti$[2.2](2,7)$ fluorenophane (17 and 18) (see Chart I).

Similar model compounds of amine-arene exciplexes require rigid skeletons linking an amine nitrogen and a polycyclic arene in such a manner that the nonbonding nitrogen electron pair is pointing toward the opposite aromatic $\pi$-electron system (Figures 1 and 2). However, the nitrogen inversion makes it difficult to locate the electron pair of aliphatic amines. An alternative is the perpendicular orientation of an aromatic nitrogen heterocycle, such as pyridine, which can interact with an opposite polycyclic arene only through its nitrogen electron pair and not through its $\pi$ electrons. These geometric requirements are fulfilled by [2](2,6)pyridino[2]paracyclophan1,9-diene (19), which together with the saturated compound (20) has been described by Boekelheide and co-workers (16-18). According to dynamic ${ }^{1} \mathrm{H}$ NMR spectroscopy, the pyridine ring in 20 is flipping between the two 


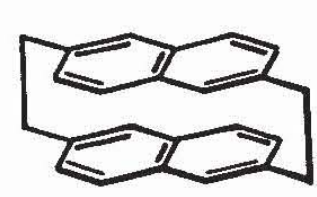

1
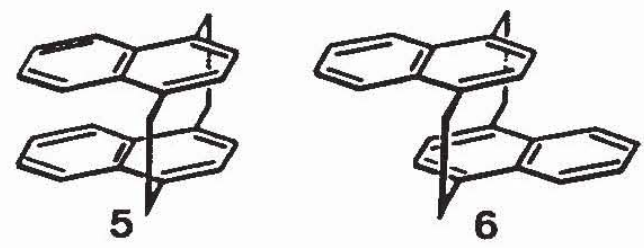

6
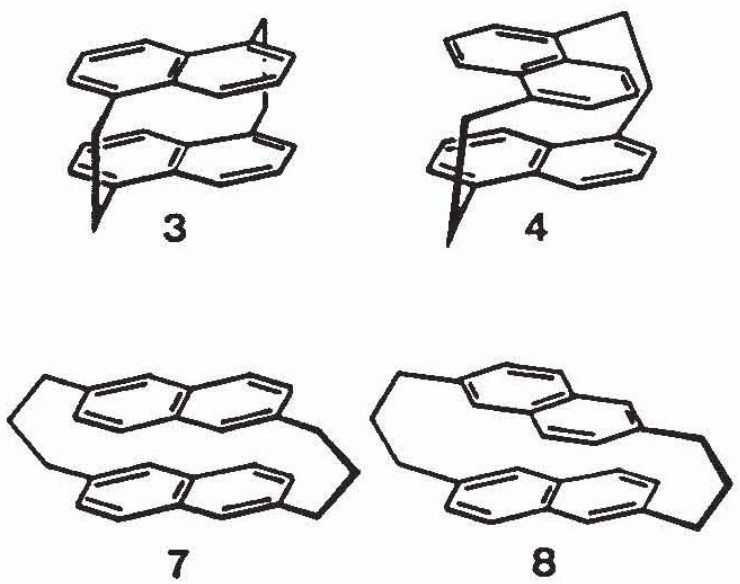

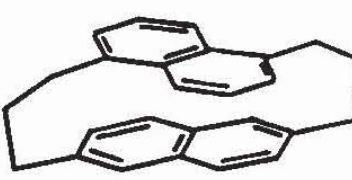

9
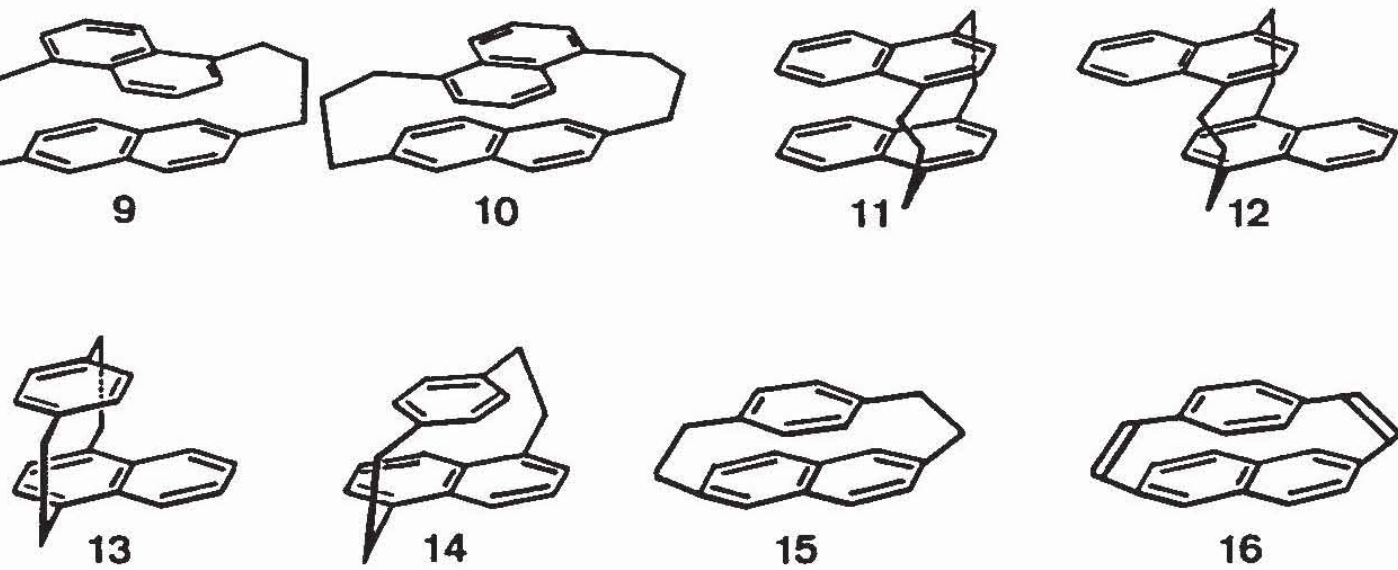

15

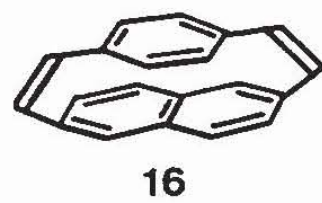

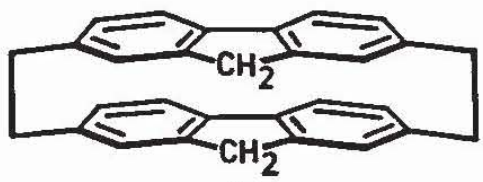

17

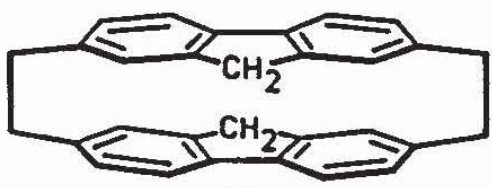

18

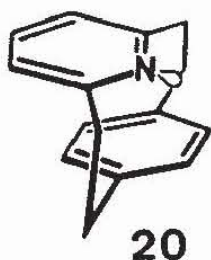

20
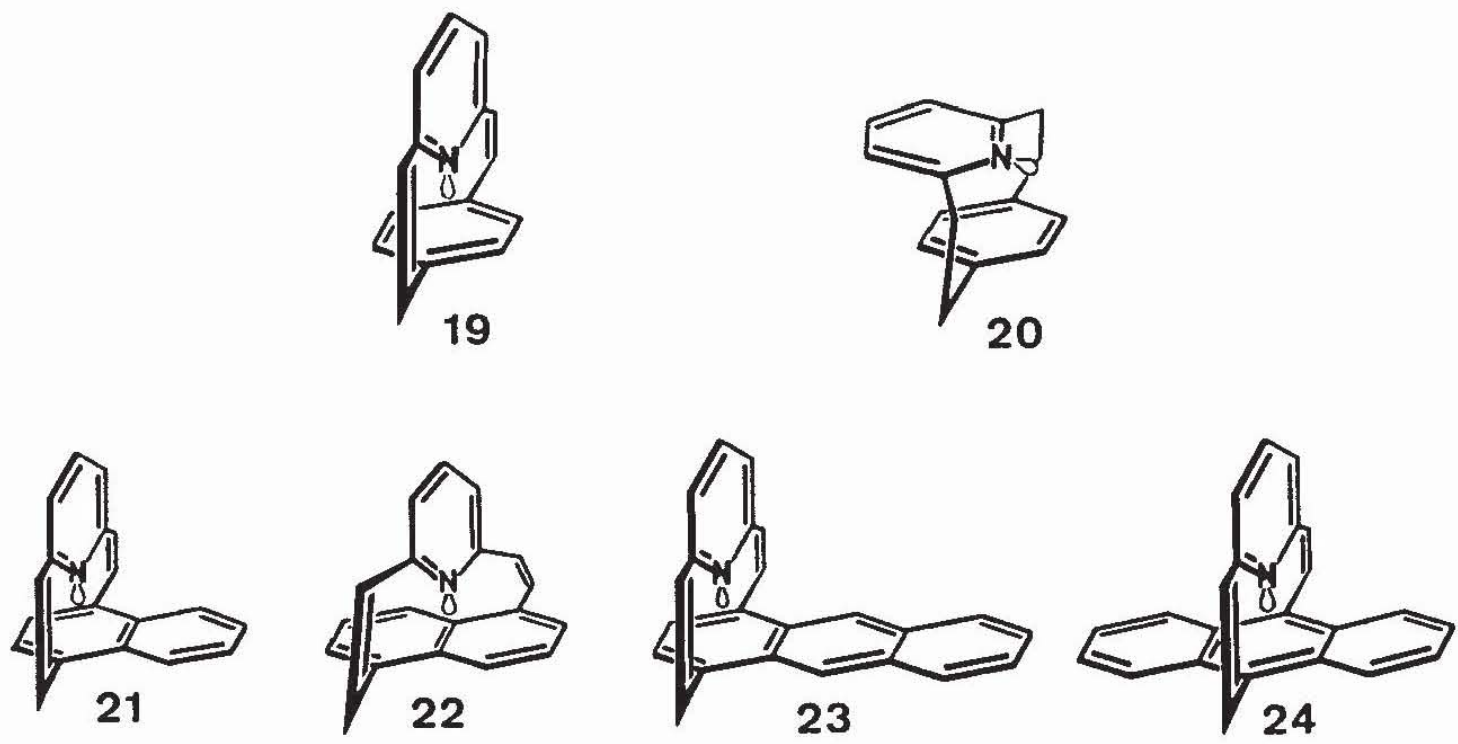

Chart I. Cyclophanes 

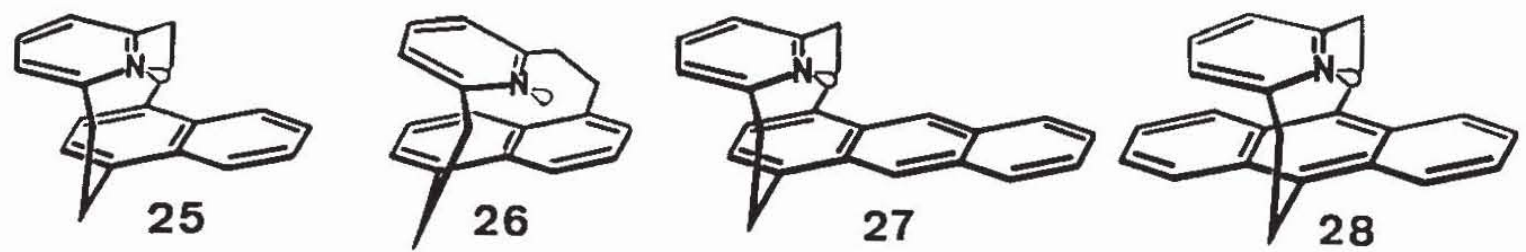

Chart I. Continued.

identical conformations in which the aromatic units have more or less parallel orientations $(16,18)$. However, for the diene $(19)$, the rectangular geometry between pyridine and benzene was found in the crystalline state (17), which apparently is also the conformation present in solution $(16,18)$. Therefore, the etheno-bridged naphthaleno- and anthracenopyridinophane systems (2124) were selected as model compounds of amine-arene exciplexes. The pairs of isomers 21 and 22 and 23 and 24 differ in that the nitrogen lone pair is interacting with different sites of the naphthalene or anthracene $\pi$-electron system. Orientational effects should be detectable in their spectroscopic properties. The corresponding ethano-bridged cyclophanes (25-28) are expected to have more parallel aromatic units. If both series of cyclophanes are compared spectroscopically, $n-\pi$ and $\pi-\pi$ electron interactions might become distinguishable.<smiles>c1ccc2ccccc2c1</smiles>

naphthalene<smiles>c1ccc2cc3ccccc3cc2c1</smiles>

anthracene

\section{Experimental Details}

The following cyclophanes were synthesized as described in the literature: achiral and chiral $[2.2](2,6)$ naphthalenophane (1 and 2, respectively; 19,20$)$; achiral and chiral $[2.2](1,5)$ naphthalenophane $(3$ and 4 , respectively; 21$)$; syn- and anti$[2.2](1,4)$ naphthalenophane $(5$ and 6 , respectively; 22,23$)$; achiral and chiral $[3.3](2,6)$ naphthalenophane $(7$ and 8 , respectively; 24$)$; $[3.3](1,5)(2,6)$ naphthalenophanes (9 and 10, respectively; 24$)$; syn- and anti-[3.2](1,4)naphthalenophane (11 and 12, respectively; 25$)$; isomeric $[2](1,4)-,[2](1,5)_{-}$, and $[2](2,6)$ naphthaleno[2]paracyclophane $(13,14$, and 15 , respectively; 26$) ;$ syn- and anti-[2.2] (2,7)fluorenophane (17 and 18, respectively; 27); isomeric [2](1,4)- and $[2](1,5)$ naphthaleno[2] $(2,6)$ pyridinophane-1,11-diene (21 and 22, respectively; 28 , $29)$; isomeric [2] $(1,4)$ - and $[2](1,5)$ naphthaleno[2] $(2,6)$ pyridinophane $(25$ and 26 , respectively; 28, 29); [2](1,4)anthraceno[2](2,6)pyridinophane-1,13-diene (23; 30); and $[2](1,4)$ anthraceno[2] $(2,6)$ pyridinophane $(27 ; 30)$.

UV spectra were obtained with a Varian spectrometer (Cary 15 and 17). Fluorescence, phosphorescence spectra, and the zero-field splitting parameters $D$ and $E$ of the triplet state were determined at $1.3 \mathrm{~K}$ with an apparatus (3I) for optical detection of magnetic resonance (ODMR) which was similar to the one described by Zuclich et al. (32). 


\section{Results and Discussion}

[2.2]-, [3.3]-, and [3.2]Naphthalenophanes. In the series of the [2.2]-, [3.3]-, and [3.2]naphthalenophanes (1-12), each structure type formed a pair of two stereoisomers (syn- and anti-isomers or diastereomers): The naphthalenophanes, linked at the naphthalene 1,4-positions by two ethano bridges or one ethano and one propano bridge, were obtained as syn-isomers 5 and 11 and anti-isomers 6 and $12(23,25)$. The naphthalene units overlap in 5 and 11 with both six-membered rings and in 6 and 12 with only one six-membered ring. Two ethano or two propano bridges at the naphthalene 2,6- or 1,5-positions generated the achiral isomers 1,3 , and 7 , in which the naphthalene units are completely eclipsed, and the chiral isomers 2,4 , and 8 , in which the naphthalene units are crossed by about $40^{\circ}(19-21,24)$. Especially interesting are the [3.3] $(1,5)(2,6)$ naphthalenophanes $(9$ and 10), which contain one 1,5- and one 2,6-bridged naphthalene unit: Two diastereomers are formed (24) in which the naphthalene units are slightly and strongly crossed (crossing angles are about $40^{\circ}$ in 9 and about $80^{\circ}$ in 10). In syn- and anti-[3.2](1,4)naphthalenophane (11 and 12), the planes of the naphthalene units are inclined to each other by about $15^{\circ}$ because the two bridges have different lengths.

Figure 3 shows the result of the X-ray structural analysis (33) of the

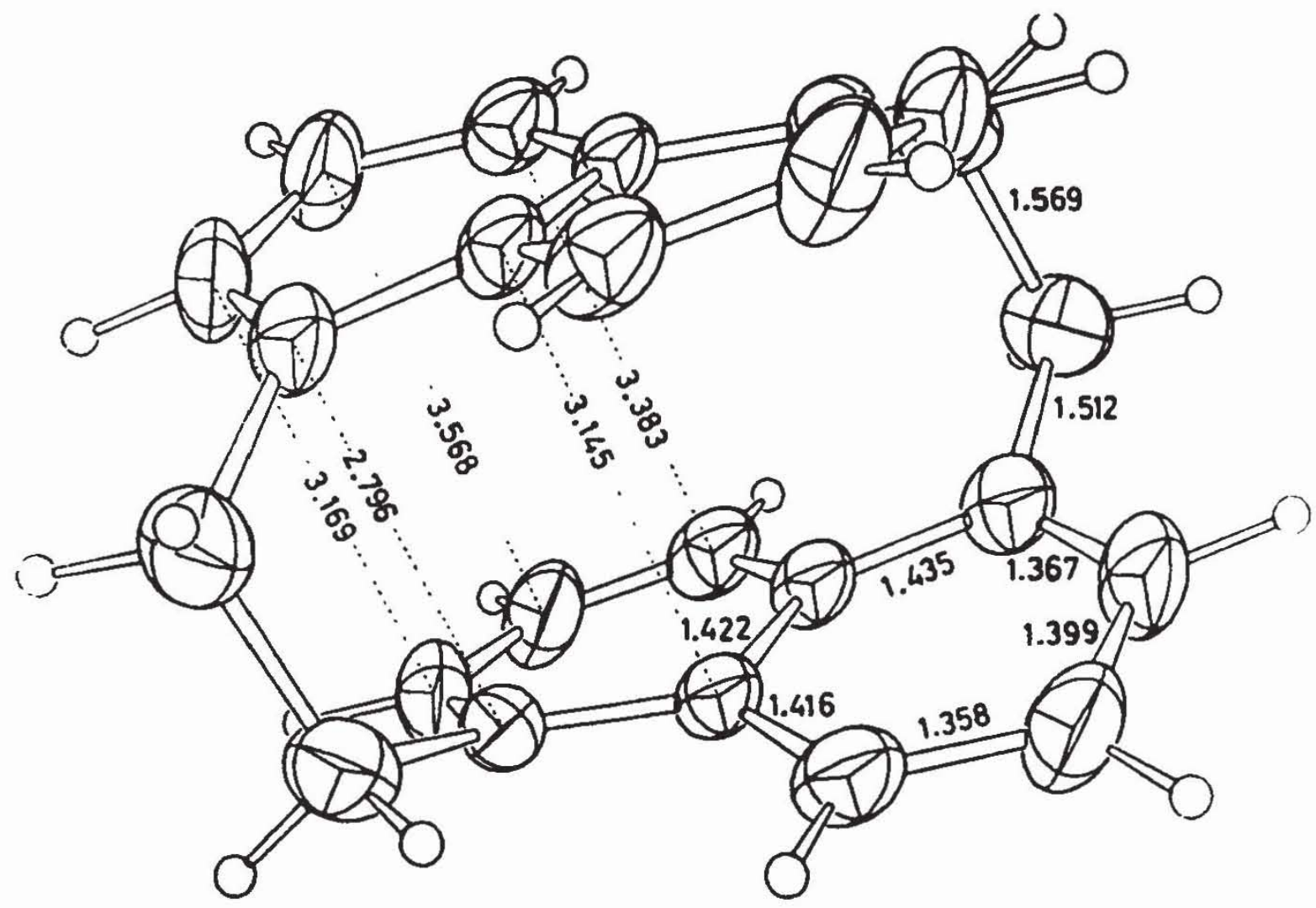

Figure 3. Molecular structure (33) of the achiral $[2.2](1,5)$ naphthalenophane

(3). 
achiral $[2.2](1,5)$ naphthalenophane (3). The naphthalene units are considerably deformed. The transannular distance varies from $2.8 \AA$ between the bridged naphthalene carbons in the 1,5-positions up to $3.6 \AA$ between the naphthalene carbons in the 3,7-positions. Certainly some contribution of the deformation on the electronic absorption and emission spectra have to be considered which cannot be separated easily from the pure electronic effects. In this regard, the less strained [3.3]naphthalenophanes are presumably the better models.

Compared with the monomeric dimethylnaphthalenes, the electronic absorption spectra of the naphthalenophanes exhibit bathochromic shifts together with the appearance of new bands and the loss of vibronic structure (19-25). As an example, Figure 4 shows the UV absorption spectra of 1, 2,

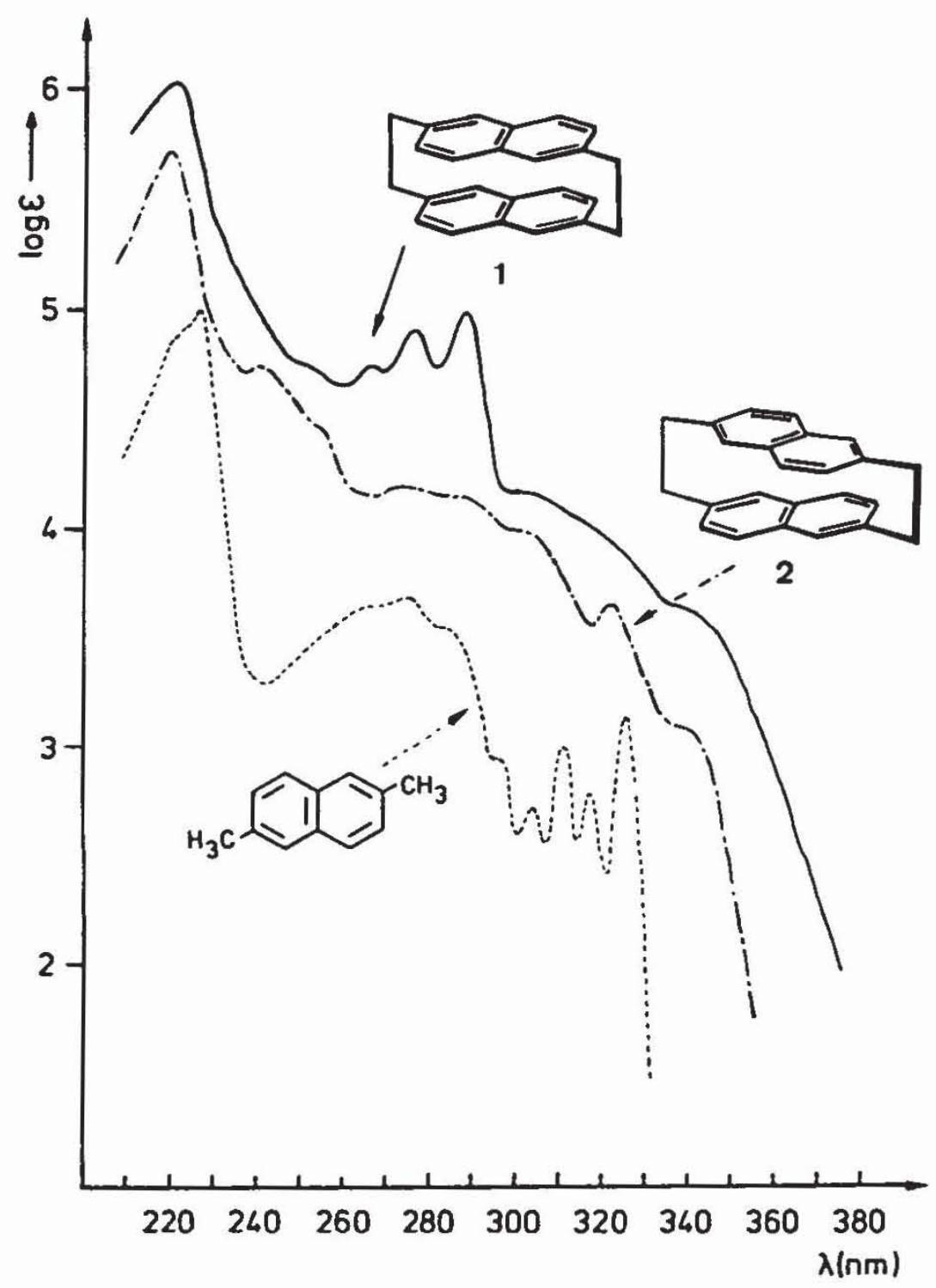

Figure 4a. UV absorption spectra of 1, 2, and 2,6-dimethylnaphthalene in cyclohexane. The spectrum of 1 is shifted by 0.5 ordinate unit, and that of 2 is shifted by 1 ordinate unit. (Reproduced with permission from reference 20. 


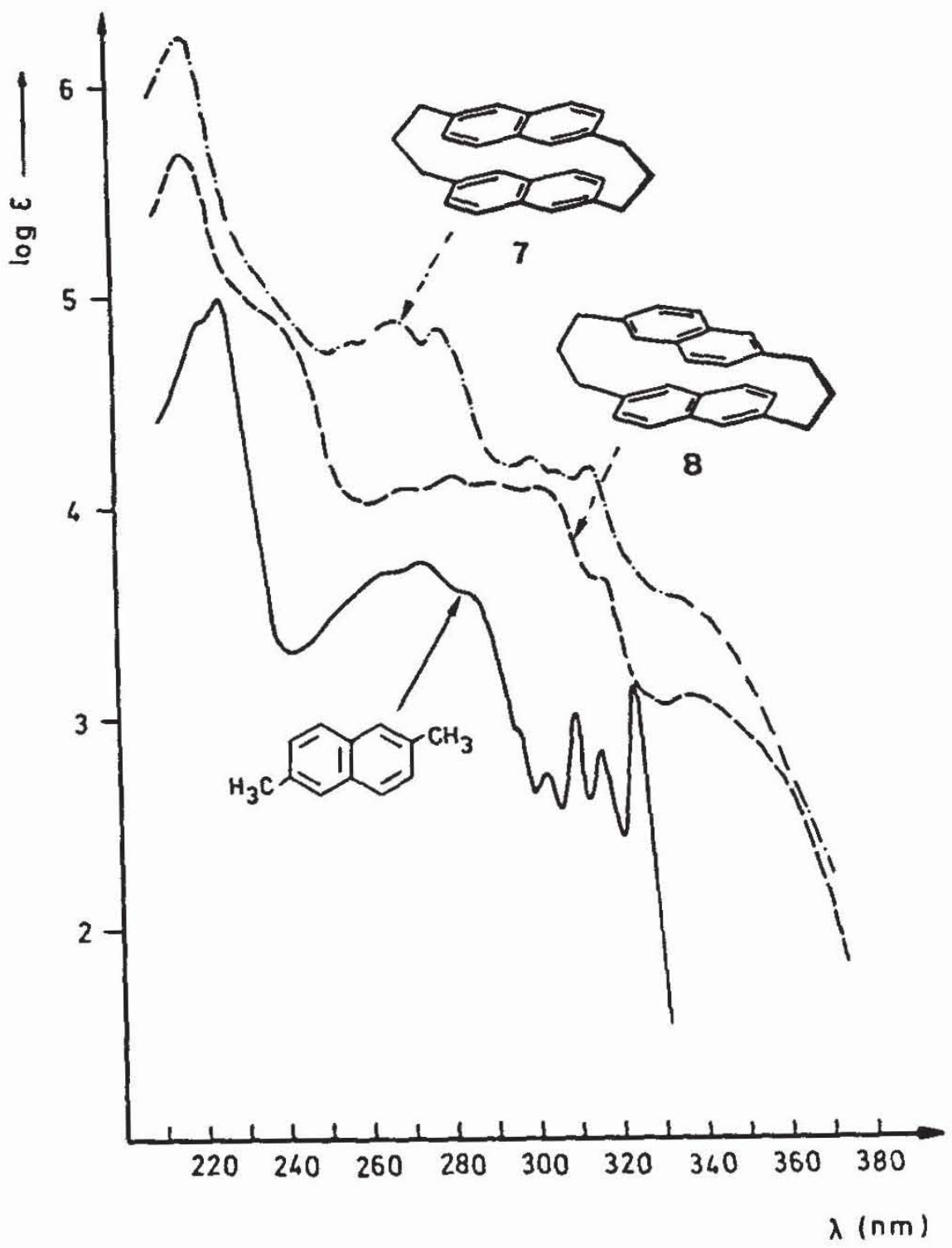

Figure $4 b$. UV absorption spectra of 7, 8, and 2,6-dimethylnaphthalene in cyclohexane. The spectrum of 7 is shifted by 0.5 ordinate unit, and that of 8 is shifted by 1 ordinate unit. (Reproduced with permission from reference 24 .

Copyright 1981 VCH Verlagsgesellschaft)

7,8 , and 2,6-dimethylnaphthalene $(19,20,24)$. In the case of the $[2.2](2,6)$ naphthalenophanes, the achiral isomer 1 exhibits a stronger bathochromic shift and hence a stronger $\pi-\pi$ electronic interaction than the chiral isomer 2, which has crossed naphthalene units. However, in the case of the $[3.3](2,6)$ naphthalenophanes, this differentation is not so clear, even though the spectra of 7 and 8 resemble those of 1 and 2 .

In the emission spectra $(31,34,35)$, the orientational effects are differentiated much more clearly (Figure 5). At $1.3 \mathrm{~K}$, monomeric 2,6-dimethylnaphthalene emits a sharply structured fluorescence from the excited singlet state $S_{1}$; however, only structureless red-shifted bands, typical of excimers and dimers, appear in the case of naphthalenophanes $1,2,7$, and 8 . The fluorescence red shift of excimers relative to the monomer, as mentioned 


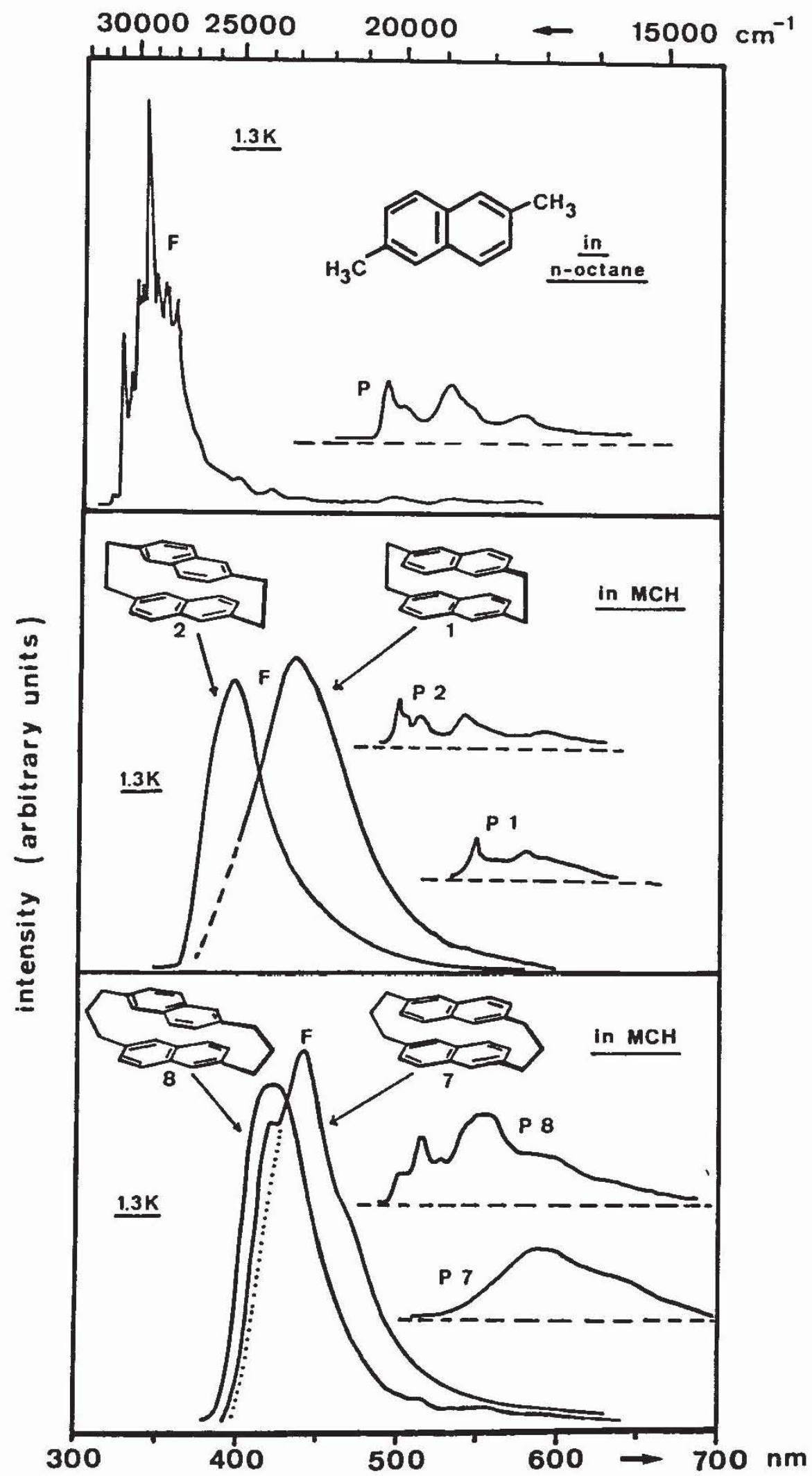

Figure 5. Fluorescence $(F)$ and phosphorescence $(P)$ of 2,6-dimethylnaphthalene and naphthalenophanes 1, 2, 7, and 8 in octane or methylcyclohexane (MCH $\mathrm{c}<10^{-3} \mathrm{~mol} / \mathrm{L}$ ) at $1.3 \mathrm{~K}$. In the fluorescence of 7, contamination by 8 apparently causes the shoulder at $23,700 \mathrm{~cm}^{-1}$, which is not observed in the emission of crystals of 7 (31). 
earlier, is proportional to the excimer binding energy in the excited singlet state $(1,12)$. In both pairs of naphthalenophanes $(1,2$ and 7,8$)$, the fluorescence red shift is found to be stronger for the achiral isomers 1 and 7 , which have eclipsed naphthalene units. Phosphorescence, the emission from the excited triplet state $T_{1}$, is also observed. The vibronic structure is partly retained, and the phosphorescence red shifts are much smaller than those found in the fluorescence $(36-38)$. However, the same gradation between isomers 1 , and 7, 8 is observed as in the fluorescence.

The excited triplet state $T_{1}$ is characterized by two unpaired electrons and is accessible to further experimental investigations because of its longer lifetime and magnetic property. As a consequence of the dipole-dipole interaction between the two unpaired electrons, the excited triplet state $T_{1}$ is split into three sublevels, $T_{x}, T_{y}, T_{z}$, even in the absence of an external magnetic field. This zero-field splitting is described by two parameters, $D$ and $E(39)$. $D$ is inversely proportional to the cube of the average distance between the two triplet electrons and is a sensitive measure for their average distance. As shown by the $D$ values for benzene $\left(0.16 \mathrm{~cm}^{-1}\right)$, naphthalene $\left(0.10 \mathrm{~cm}^{-1}\right)$, and anthracene $\left(0.07 \mathrm{~cm}^{-1}\right)$, the $D$ parameter decreases with increasing size of the $\pi$-electron system. This relationship is found because the dipole-dipole and Coulombic repulsion causes the triplet electrons to separate as far as possible. $E$ depends on the symmetry of the electron-spin distribution in the triplet state, but it is not considered in this context. In the case of the cyclophanes, the reduction of the $D$ parameter relative to the monomeric aromatic unit can be used as an additional measure for the electronic interaction in the excited triplet state $(31,34-38)$. For molecules that emit phosphorescence, the zero-field splitting parameters $D$ and $E$ of the excited triplet state can be determined by ODMR. In principle, ODMR is a double-resonance experiment between UV light and microwaves ( 31 , 40).

The fluorescence and phosphorescence red shifts and the reduction of the $D$ parameters of naphthalenophanes $1-12$ relative to the corresponding dimethylnaphthalenes are summarized in Table I. If the pairs of stereoisomers are compared (and only these should be compared), the isomer with completely eclipsed naphthalene units always has the strongest fluorescence red shift and hence the strongest bonding $\pi-\pi$ interaction in the excited singlet state. A small rotation by about $40^{\circ}$ to crossed orientations of the naphthalene units decreases the red shifts from 5500 to $3450 \mathrm{~cm}^{-1}$, from 7000 to $6300 \mathrm{~cm}^{-1}$, and from 6200 to $5200 \mathrm{~cm}^{-1}$ for the diastereomeric $[2.2](2,6)$ naphthalenophanes (1 and 2), [2.2](1,5)naphthalenophanes (3 and $4)$, and [3.3] $(2,6)$ naphthalenophanes (7 and 8$)$, respectively. However, in the case of the $[3.3](1,5)(2,6)$ naphthalenophanes $(9$ and 10$)$, the fluorescence red shift increases from $3500 \mathrm{~cm}^{-1}$ (in 9) to $3900 \mathrm{~cm}^{-1}$ (in 10) if the crossing angle between the naphthalene units is increased from about $40^{\circ}$ to about $80^{\circ}$. Apparently, the potential surface of the excited singlet state possesses a second minimum for a geometry in which the naphthalene units are strongly 
Table I. Fluorescence and Phosphorescence Red Shifts and Reductions of the Zero-Field Splitting Parameter $|D|$ of Cyclophanes in Dilute Vitreous Solutions at $1.3 \mathrm{~K}$

\begin{tabular}{lllll}
\hline \multirow{2}{*}{$\begin{array}{l}\text { Structure } \\
\text { Number }\end{array}$} & & \multicolumn{2}{c}{ Red Shift $^{b}\left(\mathrm{~cm}^{-1}\right)$} & \\
\cline { 2 - 3 } & Matrix & Fluorescence & Phosphorescence $^{a}$ & $(0 / 0)$ \\
\hline $\mathbf{1}$ & MCH & $5500 \pm 200$ & $2100 \pm 100$ & 29 \\
$\mathbf{2}$ & MCH & $3450 \pm 200$ & $300 \pm 100$ & 8 \\
$\mathbf{3}^{d}$ & PMMA $^{c}$ & $7000 \pm 200$ & $2800 \pm 100$ & 24 \\
$\mathbf{4}^{d}$ & PMMA & $6300 \pm 200$ & $1750 \pm 100$ & 11 \\
$\mathbf{7}$ & MCH & $6200 \pm 200$ & $2450 \pm 300$ & 33 \\
$\mathbf{9}$ & MCH & $5200 \pm 200$ & $400 \pm 100$ & 12 \\
$\mathbf{1 0}$ & MCH & $3500 \pm 200$ & $400 \pm 100$ & 9 \\
$\mathbf{5}$ & MCH & $3900 \pm 200$ & $1150 \pm 100$ & 15 \\
$\mathbf{6}$ & MCH & $7250 \pm 200$ & $3000 \pm 200$ & 43 \\
$\mathbf{1 1}$ & MCH & $5600 \pm 200$ & $1400 \pm 100$ & 10 \\
$\mathbf{1 2}$ & MCH & $7400 \pm 200$ & $2100 \pm 100$ & 36 \\
$\mathbf{1 4}$ & MCH & $5900 \pm 200$ & $1300 \pm 100$ & 10 \\
$\mathbf{1 5}$ & MTHF & $2500 \pm 200$ & $1900 \pm 100$ & 21 \\
$\mathbf{1 8}$ & MTHF & $1800 \pm 200$ & $1450 \pm 100$ & 6 \\
$\mathbf{1 7}$ & MTHF & $1200 \pm 200$ & $800 \pm 100$ & 9 \\
\hline
\end{tabular}

NOTE: Data for 1-12 are relative to the corresponding monomeric dimethylnaphthalenes; data for 13,14 , and 15 are relative to 1,4-, 1,5-, and 2,6-dimethylnaphthalene, respectively; and data for 17 and 18 are relative to 2,7 -dimethylfluorene.

'MCH is methylcyclohexane, PMMA is poly(methyl methacrylate), and MTHF is 2-methyltetrahydrofuran. Concentrations of the compounds in these matrices were $<10^{-3} \mathrm{~mol} / \mathrm{L}$.

${ }^{b}$ The red shifts are given between fluorescence maxima and phosphorescence $0 \rightarrow 0$ transitions. ${ }^{c}$ Reductions of $|D|$ are given as $\left[\left(|D|_{\text {mon }}-|D|\right) /|D|_{\text {mon }}\right] \times 100$.

"The structural assignments of 3 and 4 are reversed in reference 35 ; because of the X-ray structure of 3 (Figure 3) and ${ }^{1} \mathrm{H}$ NMR spectroscopy at $360 \mathrm{MHz}$, the original wrong assignments were revised $(21)$.

The fluorescence red shifts of 3 and 4 in $\mathrm{MCH}$ are $7700 \pm 200 \mathrm{~cm}^{-1}$ and $5500 \pm 200 \mathrm{~cm}^{-1}$, respectively.

SOURCE: Data are taken from references 31 and 34-38.

crossed. However, this second minimum is higher in energy than the potential well in which the two naphthalene units are fully eclipsed. Theoretical investigations of the naphthalene excimer have predicted exactly such a potential surface with a second minimum of higher energy in which the naphthalenes are crossed by about $70^{\circ}(41-43)$.

As shown by the fluorescence red shifts of the syn- and anti-isomers of [2.2]- and $[3.2](1,4)$ naphthalenophane $(5,6$ and 11,12 , respectively), the $\pi-\pi$ electronic interaction in the excited singlet state is also diminished by a translation so that the overlap of the naphthalenes is reduced from two to only one six-membered ring. The small angle, by which the naphthalene planes in 11 and 12 are inclined to each other because of the different lengths of the two bridges, apparently has only a minor effect on the excited singlet state. 
For the excited triplet state, the phosphorescence red shifts and the reductions of the $D$ parameter show a similar orientational dependence. As in the excited singlet state, the $\pi-\pi$ electronic interaction decreases if the naphthalenes are rotated from fully eclipsed to slightly crossed orientations, and it increases again to about one-half of the original amount if the rotation proceeds to strongly crossed orientations. However, this behavior is in sharp contrast with calculations. According to calculations, the naphthalene triplet excimer should be stabilized by the rotation discussed and by an inclination so that the naphthalenes in the direction of their short axes are no longer coplanar (41). The stabilization due to inclination seems to be disproved by 11 and 12, in which the angle of inclination is estimated to be $15^{\circ}$.

[2]Naphthaleno[2]paracyclophanes. In the naphthalenophanes discussed so far, two arenes of the same kind were interacting. To investigate the electronic $\pi-\pi$ interaction between arenes that differ in their electronic excitation energies, the structurally isomeric [2]naphthaleno[2]paracyclophanes (13-15) were selected as exciplex models. The para-disubstituted benzene ring is oriented differently over the naphthalene unit linked by the ethano bridges at the 1,4-, 1,5-, and 2,6-positions for 13, 14, and 15, respectively. The spectroscopic comparison of 13 and 14 seemed to be especially interesting in respect to orientational effects: In 13 , formally only one six-membered ring of the naphthalene is overlapping with the opposite benzene, whereas in 14 (and also in 15), the entire naphthalene unit is involved in the interaction. On the other hand, in 13 , the $2 p_{z}$ orbitals of the benzene carbon atoms are located directly opposite to the corresponding naphthalene carbon orbitals; therefore, the transannular overlap between these pairs of opposite $2 p_{z}$ orbitals is maximal. However, as shown by the molecular structure (33) in Figure 6, the carbon atoms of benzene and naphthalene are staggered in 14 (and also in 15). Consequently, the transannular overlap of the single carbon $2 p_{z}$ orbitals between benzene and naphthalene is expected to decrease.

In 15, the orbital overlap between benzene and naphthalene is restricted additionally by steric constraints: Because $\mathbf{1 5}$ formally is generated by connecting both ends of the shorter $p$-xylene and the longer 2,6-dimethylnaphthalene, a "bow" and a "bowstring" must be formed. The X-ray structures of 15 and its corresponding diene (16) confirm this expectation; the structures show almost planar benzene rings and extremely bent naphthalene units (44). Thus, relative to 13 and 14, the electronic interaction in 15 is expected to be smaller, whereas the extreme deformation might cause further significant spectroscopic effects. Especially because the diene (16) now can be prepared in reasonable yields, the properties of these highly strained compounds are being studied in more detail (44).

The results of emission spectroscopy and the ODMR measurements of 13-15 are summarized in Table I (31). Relative to the corresponding 1,4-, 1,5-, and 2,6-dimethylnaphthalenes, the fluorescence and phosphorescence 

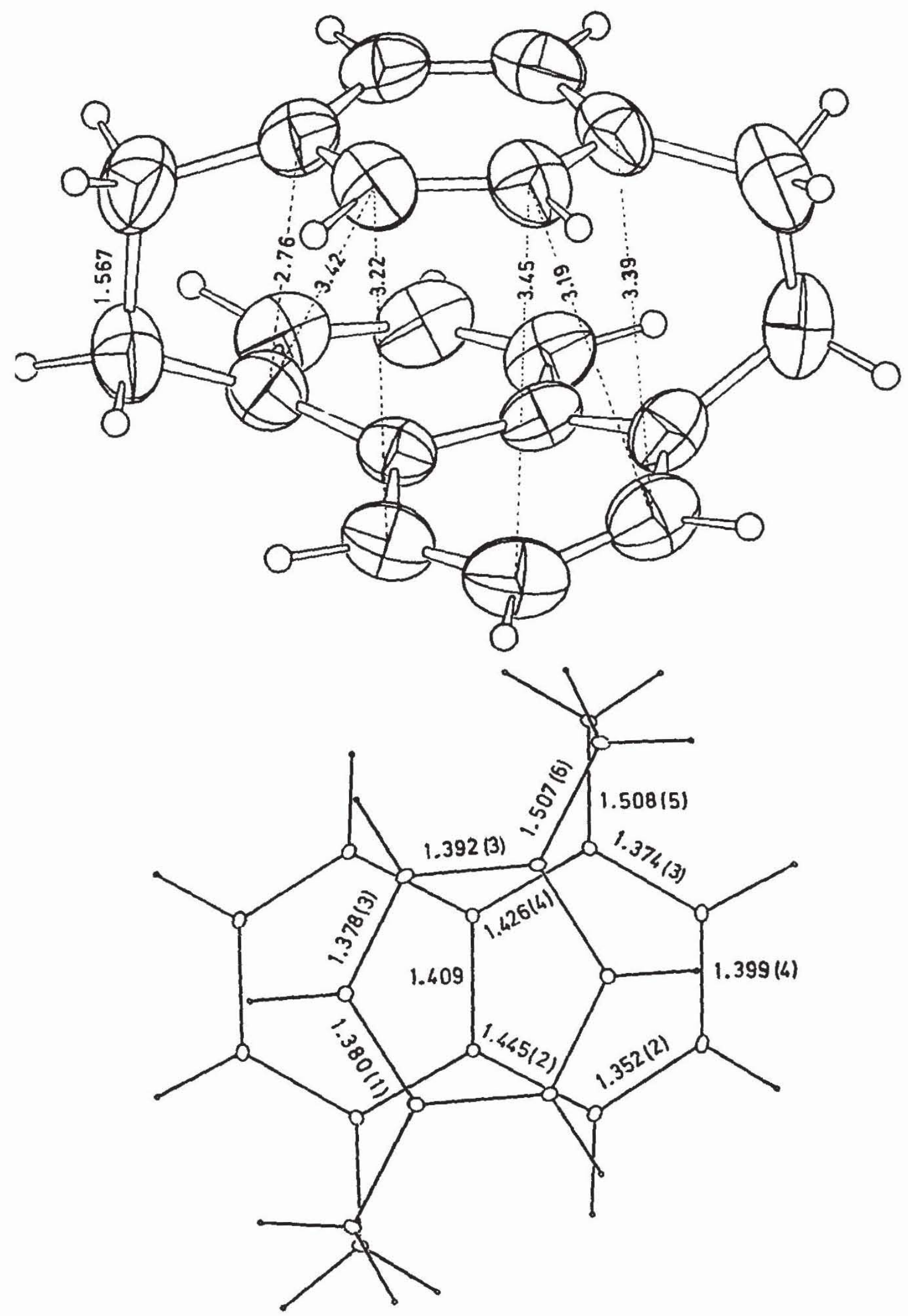

Figure 6. Molecular structure (33) of [2](1,5)naphthalen[2]paracyclophane (14). 
red shifts of 13-15 decrease in the order $13>14>15$. This sequence means that both in the excited singlet and triplet states, the electronic $\pi-$ $\pi$ interaction between benzene and naphthalene is highest if, as in 13, the carbon atoms of benzene and naphthalene are eclipsed to enable maximal overlap between each pair of opposite carbon $2 p_{z}$ orbitals (36). In contrast with the order of the phosphorescence red shifts, 15 exhibits a stronger reduction of the $D$ parameter than 14. The extreme deformation of the naphthalene unit in $\mathbf{1 5}$ might be responsible for an additional reduction of the $D$ parameter (45).

Compared with the [2.2]naphthalenophanes (1-6), the fluorescence red shifts of the naphthalenoparacyclophanes 13-15 are much smaller, whereas the phosphorescence red shifts are about the same magnitude (Table I). Especially interesting is the comparison between 13 and 6, which have comparable structures with 1,4-disubstituted benzene and naphthalene units, respectively. Whereas the fluorescence red shift of naphthalenoparacyclophane 13 is less than one-half of that for naphthalenophane 6 , the phosphorescence of 13 has a $500-\mathrm{cm}^{-1}$ larger red shift. Apparently, in 13, the excited triplet state is additionally lowered in energy by contributions of configuration interaction with higher excited states and/or by chargetransfer terms (31). In agreement with an additional energy decrease through charge-transfer terms, the reduction of the $D$ parameter in 13 relative to 1,4-dimethylnaphthalene is $21 \%$, which is more than twice as large as the $10 \%$ reduction for $6(31,46)$.

syn- and anti-[2.2](2,7)Fluorenophane. As a further example to study the orientational dependence of the $\pi-\pi$ interaction between polycyclic arenes, syn- and anti-[2.2](2,7)fluorenophane (17 and 18) were synthesized (27). Because of the five-membered ring, the 2,7-substituents of fluorene form an angle of $155^{\circ}$. This geometry causes the fluorene units to be eclipsed in the syn-isomer (17) and staggered in the anti-isomer (18). As shown by the molecular structure of 18 (Figure 7), the fluorene units are considerably bent outward. Therefore, the transannular distances in the central region of the molecule are unusually large $(3.63 \AA$ between the planes of the five-membered rings). The transannular overlap between the carbon $2 p_{z}$ orbitals should be significant mainly in the neighborhood of the bridges. From the projection at the bottom of Figure 7, the staggered arrangement of the fluorene carbon atoms is evident. Because the carbon atoms and their $2 p_{z}$ orbitals must be eclipsed in the $s y n$-isomer (17), a larger $\pi-\pi$ interaction is expected for the syn-isomer (17) than for the anti-isomer (18).

The emission spectroscopy and ODMR measurements summarized in Table I for 17 and 18 confirm these expectations (the spectra are shown in references 37 and 38). According to the fluorescence red shifts of 3900 and $2600 \mathrm{~cm}^{-1}$, the electronic interaction in the excited singlet state is larger in the syn-isomer (17) than in the anti-isomer (18). As was already observed in 

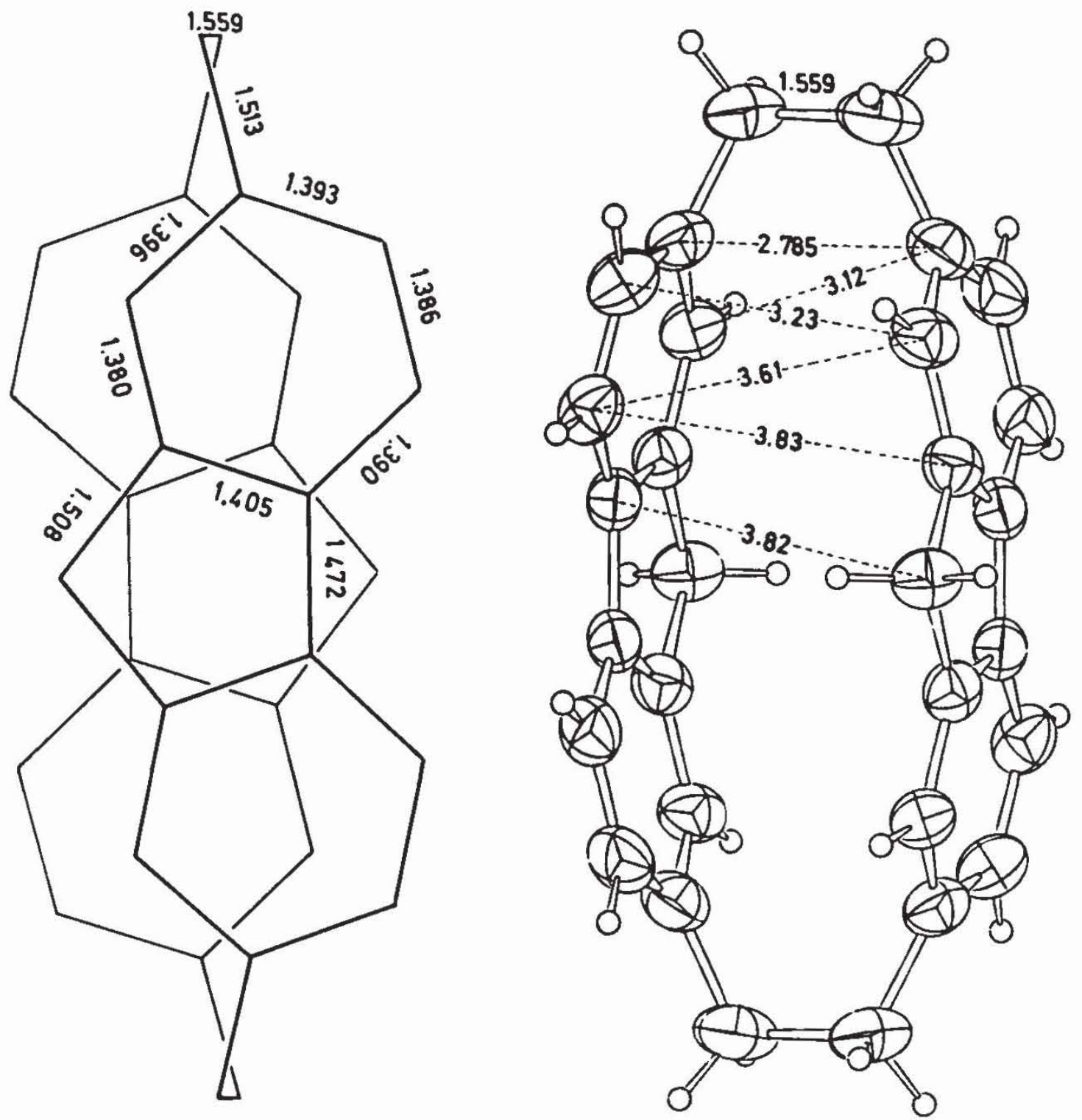

Figure 7. Molecular structure of anti-[2.2](2,7)fluorenophane (18). (Reproduced with permission from reference 27. Copyright $1985 \mathrm{VCH}$ Verlagsgesellschaft)

the case of the naphthalenophanes, the $\pi-\pi$ interaction in the excited triplet state $T_{1}$ is considerably smaller than in the excited singlet state $S_{1}(36-38)$; however, the orientational dependence of the electronic interaction is similar in both excited states.

By reaction with $n$-butyllithium, 17 and 18 can be converted into the red syn- and anti-[2.2](2,7)fluorenophane dianions in which the electronrich 9-fluorenyl anions are the interacting arenes (27). A second example of such double-layered dianions, the $[2.2](4,7)$ indenophane dianion, has been described recently (47).

Naphthalenopyridinophanes and Anthracenopyridinophanes. As model compounds for amine-arene exciplexes, isomeric [2] $(1,4)$ - and [2](1,5)naphthaleno[2] $(2,6)$ pyridinophane-1,11-diene (21 and 
22), and for comparison the corresponding saturated naphthalenopyridinophanes (25 and 26) were synthesized $(28,29)$. ${ }^{1} \mathrm{H}$ NMR and X-ray structural analysis indicated that the etheno bridges in 21 and 22 indeed enforce the required rectangular geometry between naphthalene and pyridine (28). According to the X-ray structural analysis (Figure 8, middle), 22 exhibits rectangular geometry; it has an interplanar angle of $87^{\circ}$ for one of the two independent molecules in the unit cell. Because of packing, this angle is $65^{\circ}$ for the second molecule (Figure 8, right). On the other hand, for the corresponding cyclophane (26) linked by ethano bridges, interplanar angles of $24^{\circ}$ and $29^{\circ}$ are observed in the two independent molecules of the unit cell (Figure 8, left). Because of these different conformations, $n-\pi$ interaction is expected to exist exclusively in the etheno-bridged naphthalenopyridinophanes (21 and 22), whereas $\pi-\pi$ interaction should be dominant in the ethano-bridged compounds ( 25 and 26).

This difference in the electronic interaction and strong orientational effects are indicated by the electronic absorption and emission spectra of the two pairs of isomers (21, 22 and 25, 26). In the UV spectra (Figure 9), the two dienes (21 and 22) exhibit enormous bathochromic shifts relative to the monomeric dimethylnaphthalenes and 2,6-dimethylpyridine. The absorption edge for the yellow 22 is shifted $50 \mathrm{~nm}$ to longer wavelengths than for the colorless 21. This difference is due only to the different location of the nitrogen electron pair: In the first case it is directly over the central naphthalene $\pi$ bond, and in the second case it is over the electronic hole in the center of a naphthalene six-membered ring. The ethano-bridged cyclophanes (25 and 26) also show absorptions shifted to longer wavelengths, but on the whole the bathochromic shifts observed for the $\pi-\pi$ interaction are much smaller than for the $n-\pi$ interaction.

In the fluorescence emission at $1.3 \mathrm{~K}$ (Figure 10), these differences are
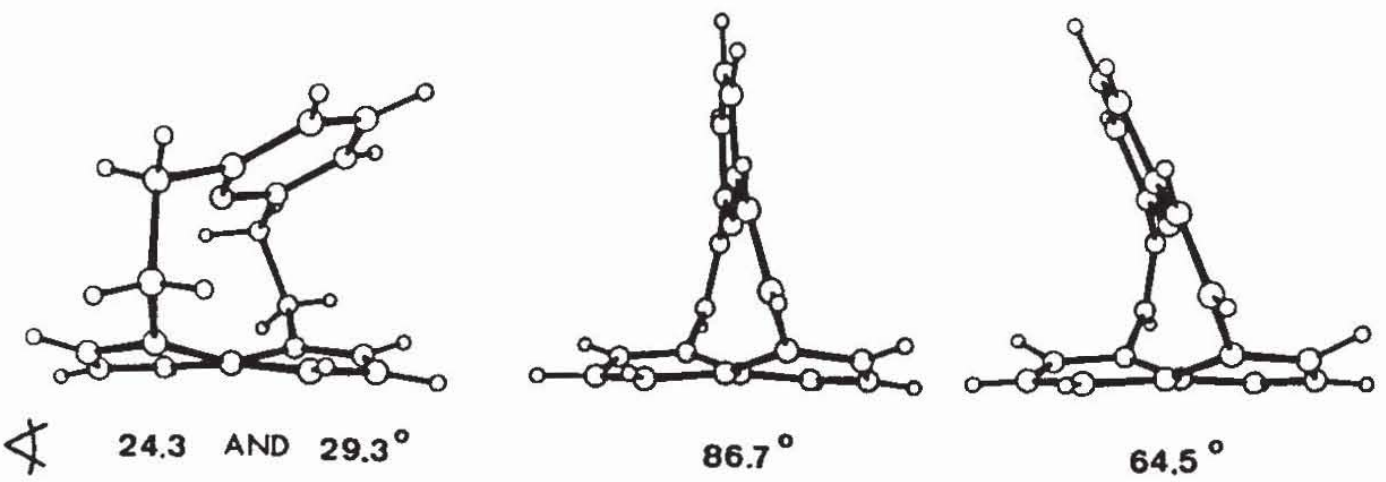

Figure 8. Molecular structures of [2](1,5)naphthaleno[2](2,6)pyridinophane1,11-diene (22, two independent molecules, middle and right) and $[2](1,5)$ naphthaleno[2] $(2,6)$ pyridinophane $(26$, left). The interplanar angles between naphthalene and pyridine are given for each pair of the two independent molecules 22 and 26 in the unit cells. (Reproduced with permission from reference 28. Copyright $1985 \mathrm{VCH}$ Verlagsgesellschaft) 


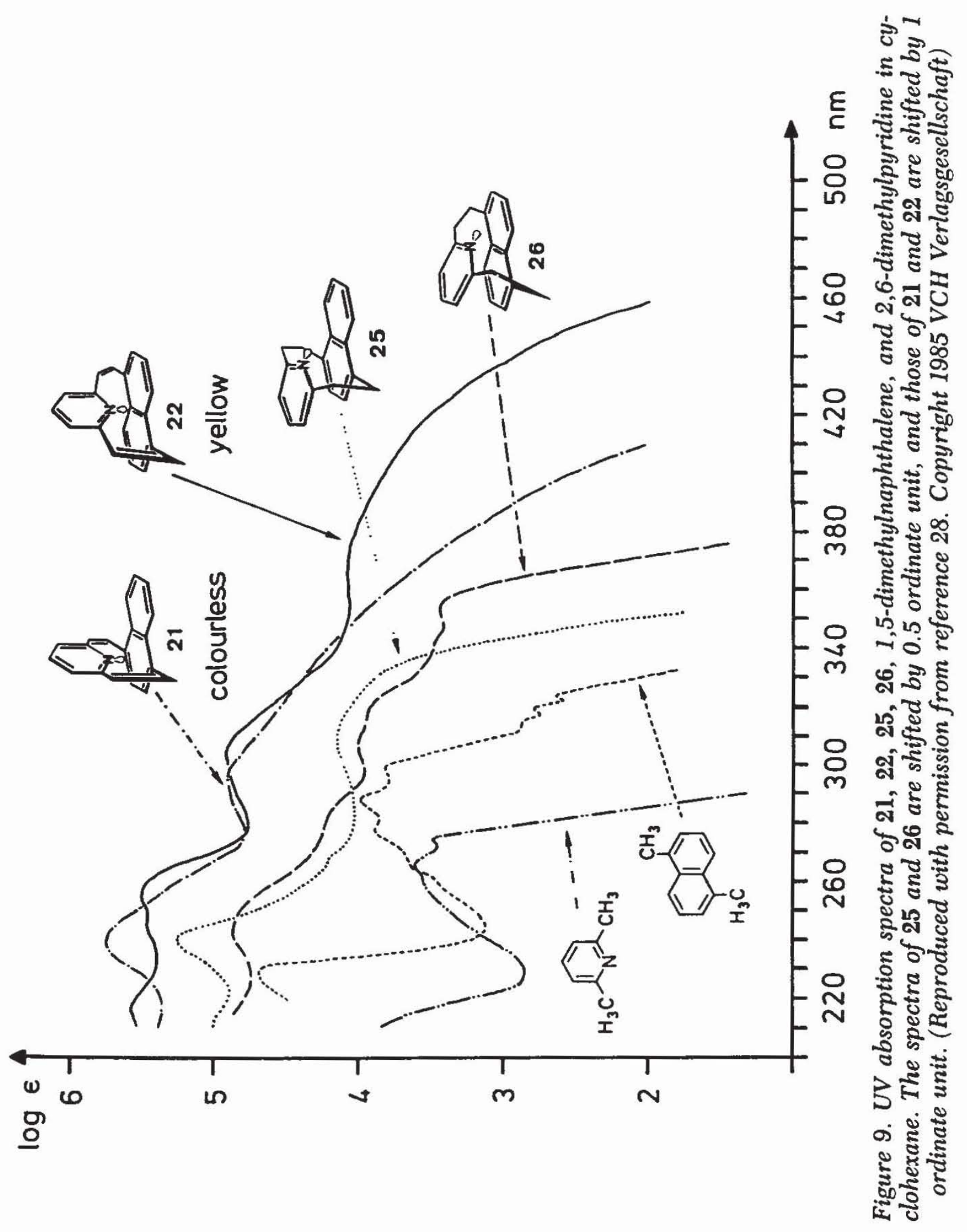




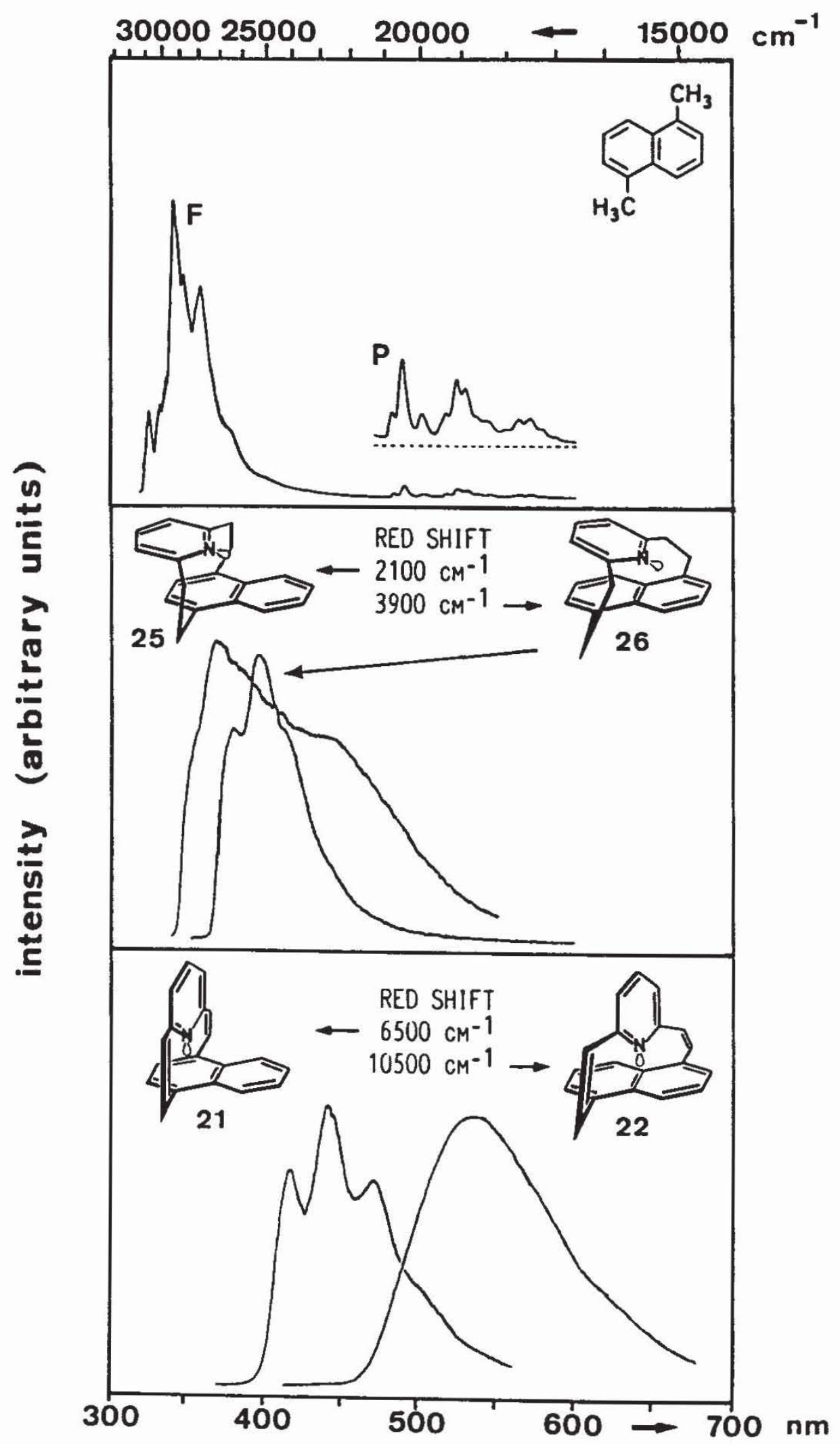

Figure 10. Emission spectra of 1,5-dimethylnaphthalene, 21, 22, 25, and 26 in $\mathrm{n}$-octane (c $<10^{-3} \mathrm{~mol} / \mathrm{L}$ ) at $1.3 \mathrm{~K}$. (Reproduced with permission from reference 28. Copyright 1985 VCH Verlagsgesellschaft) 
even more pronounced. Compared with the structured fluorescence of the corresponding dimethylnaphthalenes, the ethano-bridged cyclophanes (25 and 26) possess fluorescence red shifts of 2100 and $3900 \mathrm{~cm}^{-1}$, respectively. Compared with the naphthalenophanes (1-12), these values correspond to $\pi-\pi$ interactions of moderate size.

The red shifts observed for the etheno-bridged cyclophanes (21 and 22) are much stronger; they reach $6500 \mathrm{~cm}^{-1}$ in 21 and the enormous value of $10,500 \mathrm{~cm}^{-1}$ in 22 . Fluorescence red shifts of this magnitude usually are observed only in charge-transfer complexes between donor- and acceptorsubstituted arenes (46). The spectroscopic difference of $4000 \mathrm{~cm}^{-1}$ between the isomers 21 and 22 corresponds to about $11 \mathrm{kcal} / \mathrm{mol}(47 \mathrm{~kJ} / \mathrm{mol})$. Because no phosphorescence could be detected for all the naphthalenopyridinophanes, the excited triplet states could not be investigated by ODMR techniques (48).

In the case of the anthracene compounds, so far we could synthesize only [2] $(1,4)$ anthraceno[2] $(2,6)$ pyridinophane-1,13-diene (23) and the corresponding ethano-bridged compound (27); in both of these compounds, pyridine is arranged over an outer anthracene ring (30). Therefore, a comparison of nitrogen over an outer anthracene ring, as in 23 , with nitrogen over the inner anthracene ring, as in $\mathbf{2 4}$, is not yet possible. However, anthracenopyridinophane 23 can be compared with naphthalenopyridinophane 21 , both of which have the same geometric arrangement of the nitrogen lone pair over the center of an aromatic six-membered ring. Relative to 1,4-dimethylanthracene, the fluorescence of 23 is red-shifted by $4500 \pm 500 \mathrm{~cm}^{-1}$ (the spectra are shown in reference 30 ). This red shift is considerably less than the red shift of $6500 \pm 300 \mathrm{~cm}^{-1}$ for the fluorescence of 21 relative to 1,4 dimethylnaphthalene (28). Actually, a priori, one could have expected the reverse order for 21 and 23 because anthracene is a much better electron acceptor than naphthalene; thus, a charge transfer from the occupied nonbonding nitrogen orbital to the lowest unoccupied molecular orbital of anthracene should be preferred.

An explanation of the experimental result is attempted by adapting a bonding model that previously has been used by Colpa et al. (36) to describe the excimer-type $\pi-\pi$ bonding in cyclophanes. According to this model, the bonding in the excited singlet state between naphthalene (29) or anthracene (30) and an amine nitrogen, which is located over the center of an aromatic six-membered ring, can be described by $\sigma$-type bonds between the nitrogen orbital and the six carbon $2 p_{z}$ orbitals (Figure 11). Then, the total bond density $\left(d_{t}{ }^{n \pi}\right)$ is the sum of these six contributions, which again are described by a product of two quantities, $P_{i j}$ and $F_{i j}$. The quantity $P_{i j}$ is essentially geometric quantity (36) and therefore should be identical or very similar in the naphthalene and anthracene exciplex models (21 and 23, respectively). The quantity $F_{i j}$ is the charge or electron density, that is, the probability of finding an electron on each single center. As an approximation (36), the spin 
densities of the naphthalene and anthracene radical anions are used; these can be calculated $(49,50)$ or determined experimentally (51-53). As shown in Table II, the spin density in the 1-position of naphthalene is twice as large as that of anthracene; in addition, the spin density in the 2-position of naphthalene is also larger than that of anthracene. Therefore, in comparison with 21 , a smaller total bond density $d_{t}{ }^{n \pi}$ in the excited singlet state and hence a smaller fluorescence red shift are predicted for the anthracenopyridinophane (23); these predictions are in accordance with the experimental results. On the other hand, the very high spin density in the anthracene 9,10-positions should cause a strong exciplex bond if the nitrogen electron pair is located over the inner anthracene ring. For $[2](9,10)$ anthraceno[2](2,6)pyridinophane-1,13-diene (24), which is the isomer of 23 and could not yet be synthesized, a fluorescence red shift that is larger than that for 23 and presumably exceeding that for 21 is predicted.

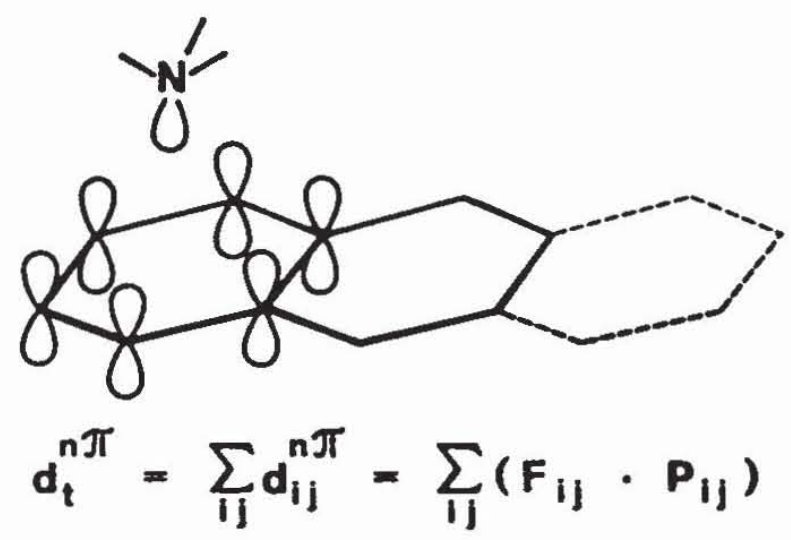

Figure 11. Bonding model for amine-arene exciplexes.

Table II. Calculated Spin Densities for the Radical Anions (Cations) of Naphthalene and Anthracene

\begin{tabular}{lll}
\hline $\mathbf{n}$ & $\mathbf{c}_{\text {in }}$ & $\boldsymbol{\rho}_{\mathbf{z}}$ \\
\hline & Naphthalene & \\
1 & 0.181 & 0.222 \\
2 & 0.069 & 0.047 \\
9 & 0 & -0.037 \\
& Anthracene & \\
1 & 0.097 & 0.118 \\
2 & 0.048 & 0.032 \\
9 & 0.193 & 0.256 \\
11 & 0.008 & -0.028 \\
\hline
\end{tabular}

NOTE: $n$ is the position of the carbon in naphthalene or anthracene (see structure 29 or 30 , respectively); $c^{2}{ }_{\text {in }}$ is the HMO (Hückel molecular orbital) spin density, which is the square of the LCAO (linear combination of atomic orbitals) coefficient of the single-occupied HMO $\psi_{i}$ at the center $n$ (49); and $\rho_{n}$ is the McLachlan spin density (50).

SOURCE: Reproduced with permission from reference 30 . Copyright 1986 Verlag der Zeitschrift für Naturforschung. 


\section{Conclusions}

The orientation of interacting aromatic $\pi$-electron systems strongly influences the extent of the electronic interaction. The investigations of naphthalenophanes (1-12), naphthalenoparacyclophanes (13-15), and fluorenophanes (17-18) indicate that in the excited singlet state, as well as in the excited triplet state, the $\pi-\pi$ interactions between two arenes are the highest if their planes are parallel and the maximal number of their sixmembered rings are completely eclipsed. This geometry enables maximal overlap between the single pairs of carbon $2 p_{z}$ orbitals located directly opposite each other. Similarly, the $n-\pi$ interaction in the amine-arene exciplex models (21-23), in which the nitrogen electron pair is pointing toward aromatic $\pi$-electron systems, is determined by the overlap between the lonepair orbital and each of the carbon $2 p_{z}$ orbitals involved. A simple model using the spin densities of aromatic radical anions is useful to predict the $n-\pi$ interactions in the amine-arene exciplexes.

\section{Acknowledgment}

The investigations described were started within the group of $\mathrm{H}$. A. Staab at the University of Heidelberg and at the Max-Planck-Institut für medizinische Forschung, Heidelberg; they were continued at the Max-Planck-Institut für Kohlenforschung, Mülheim/Ruhr. We thank H. A. Staab and K. H. Hausser, Max-Planck-Institut für medizinische Forschung, Heidelberg, for generous support and detailed discussions. The excellent contributions of our co-workers and colleagues (their names are listed in our cited papers) are gratefully acknowledged. The work was supported by Fonds der Chemischen Industrie, Frankfurt am Main, and Deutsche Forschungsgemeinschaft, Bad Godesberg. Petroleum Research Fund Grant No. 18537-SE covered travel expenses to the ACS National Meeting in Anaheim, CA, where this research was presented.

\section{References}

1. Förster, Th. Angew. Chem. 1969, 81, 364; Angew. Chem. Int. Ed. Engl. 1969, $8,333$.

2. Stevens, B. Adv. Photochem. 1971, 8, 161.

3. Organic Molecular Photophysics; Birks, J. B., Ed.; Wiley: New York, 1973, 1975; Vols. 1, 2.

4. The Exciplex; Gordon, M.; Ware, W. R., Eds.; Academic: New York, 1975.

5. Molecular Association; Foster, R., Ed.; Academic: New York, 1975, 1979; Vols. $1,2$.

6. Kuzmin, M. G.; Guseva, L. N. Chem. Phys. Lett. 1969, 3, 71.

7. Nakashima, N.; Mataga, N.; Ushio, F.; Yamanaka, C. Z. Phys. Chem. (Frankfurt-Main) 1972, 79, 150.

8. Chandross, A.; Thomas, H. T. Chem. Phys. Lett. 1971, 9, 393.

9. Davidson, R. S. J. Chem. Soc., Chem. Commun. 1969, 1450. 
10. Baltrop, J. A.; Owers, R. J. J. Chem. Soc., Chem. Commun. 1970, 1462.

11. Förster, Th.; Kasper, K. Z. Phys. Chem. (Frankfurt-Main) 1964, 1, 275.

12. Stevens, B.; Ban, M. I. Trans. Faraday Soc. 1964, 60, 1515.

13. Rebafka, W.; Staab, H. A. Angew. Chem. 1974, 86, 234; Angew. Chem. Int. Ed. Engl. 1974, 13, 203.

14. Cyclophanes I and II; Keehn, P. M.; Rosenfeld, S. M., Eds.; Academic: New York, 1983; Vols. 1, 2.

15. Vögtle, F., Ed. Top. Curr. Chem. 1983, 113, 115.

16. Boekelheide, V.; Galuszko, K.; Szeto, K. S. J. Am. Chem. Soc. 1974, 96, 1578.

17. Weaver, L. H.; Matthews, B. W. J. Am. Chem. Soc. 1974, 96, 1581.

18. Reingold, I. D.; Schmidt, W.; Boekelheide, V. J. Am. Chem. Soc. 1979, 101, 2121.

19. Haenel, M. W.; Staab, H. A. Chem. Ber. 1973, 106, 2203.

20. Blank, N. E.; Haenel, M. W. Chem. Ber. 1983, 116, 827.

21. Haenel, M. W. Chem. Ber. 1978, 111, 1789.

22. Cram, D. J.; Dalton, C. K.; Knox, G. R. J. Am. Chem. Soc. 1963, 85, 1088.

23. Wasserman, H. H.; Keehn, P. M: J. Am. Chem. Soc. 1969, 91, 2374.

24. Blank, N. E.; Haenel, M. W. Chem. Ber. 1981, 114, 1520.

25. Blank, N. E.; Haenel, M. W. Chem. Ber. 1981, 114, 1531.

26. Haenel, M. W. Chem. Ber. 1982, 115, 1425.

27. Haenel, M. W.; Irngartinger, H.; Krieger, C. Chem. Ber. 1985, 118, 144.

28. Haenel, M. W.; Lintner, B.; Benn, R.; Rufińska, A.; Schroth, G.; Krüger, C.; Hirsch, S.; Irngartinger, H.; Schweitzer, D. Chem. Ber. 1985, 118, 4884.

29. Haenel, M. W.; Lintner, B.; Benn, R.; Rufińska, A.; Schroth, G. Chem. Ber. $1985,118,4922$.

30. Haenel, M. W.; Lintner, B.; Schweitzer, D. Z. Naturforsch. 1986, 31b, 223.

31. Schweitzer, D. Habilitationsschrift, University of Heidelberg, 1980.

32. Zuclich, J.; Schweitzer, D.; Maki, A. H. Photochem. Photobiol. 1973, 18, 161.

33. Irngartinger, $\mathbf{H}$.; University of Heidelberg, in preparation.

34. Schweitzer, D.; Colpa, J. P.; Behnke, J.; Hausser, K. H.; Haenel, M. W.; Staab, H. A. Chem. Phys. 1975, 11, 373.

35. Schweitzer, D.; Colpa, J. P.; Hausser, K. H.; Haenel, M. W.; Staab, H. A. J. Lumin. 1976, 12/13, 363.

36. Colpa, J. P.; Hausser, K. H.; Schweitzer, D. Chem. Phys. 1978, 29, 187.

37. Schweitzer, D.; Hausser, K. H.; Haenel, M. W. Chem. Phys. 1978, 29, 181.

38. Schweitzer, D.; Haenel, M. W. Chem. Ber. 1985, 118, 163.

39. McGlynn, S. P.; Azumi, T.; Kinoshita, M. Molecular Spectroscopy of the Triplet State; Prentice Hall: Englewood Cliff, N.J., 1969.

40. Hausser, K. H.; Wolf, H. C. Adv. Magn. Reson. 1976, 8, 85.

41. Chandra, A. K.; Lim, E. C. Chem. Phys. Lett. 1977, 45, 79.

42. Chandra, A. K.; Sudhindra, B. S. Mol. Phys. 1974, 28, 695.

43. Azumi, T.; Azumi, H. Bull. Chem. Soc. Jpn. 1966, 39, 1829, 2317.

44. Haenel, M. W.; Blank, N. E.; Wientges, H.; Krüger, C.; in preparation.

45. Wasserman, E.; Hutton, R. S.; Bramwell, F. B. J. Am. Chem. Soc. 1976, 98, 7529.

46. Schweitzer, D.; Hausser, K. H.; Taglieber, V.; Staab, H. A. Chem. Phys. 1976, $14,183$.

47. Frim, R.; Raulfs, F.-W.; Hopf, H.; Rabinovitz, M. Angew. Chem. 1986, 98, 160; Angew. Chem. Int. Ed. Engl. 1986, 25, 174.

48. Lintner, B.; Schweitzer, D.; Benn, R.; Rufińska, A.; Haenel, M. W. Chem. Ber. $1985,118,4907$.

49. Heilbronner, E.; Bock, H. Das HMO-Modell und seine Anwendung; Grundlagen und Handhabung; 2nd ed.; Verlag Chemie: Weinheim, 1978; Vol. 1, p 267. 
19. HAENEL \& SCHWEITZER Electronic Interactions in Cyclophanes 355

50. McLachlan, A. D. Mol. Phys. 1960, 3, 233.

51. Bolton, J. R.; Fraenkel, G. K. J. Chem. Phys. 1964, 40, 3307.

52. Snyder, L. C.; Amos, T. J. Chem. Phys. 1965, 42, 3670.

53. Gerson, F.; Weidmann, B.; Heilbronner, E. Helv. Chim. Acta 1964, 47, 1951.

RECEIVED for review November 11, 1986. ACCEPTED January 27, 1987. 